\title{
Propylene Oxide-Ethylene Oxide Block Polymer as a Surfactant for Cloud Point Extraction of Some Metal Ions
}

\author{
Abdelsalam Asweisi, Rihab Hussein, Nabil Bader*, Rajab Elkailany
}

Chemistry Department, Faculty of Science, Benghazi University, Benghazi, Libya

\section{AR T I C L E I N F O}

Received: 03 July 2019

Revised: 25 July 2019

Accepted: 01 September 2019

Available online: 05 September 2019

\section{K E Y W O R D S}

Cloud point extraction

Propylene oxide-ethylene oxide block polymer

APDC

\section{A B S T R A C T}

Propylene oxide-ethylene oxide block polymer (PO-EO) is a surfactant with low cloud point. It has been used for separation of $\mathrm{Cu}^{2+}, \mathrm{Fe}^{3+}, \mathrm{Mn}^{2+}, \mathrm{Cd}^{2+}$ and $\mathrm{Cr}^{3+}$ ions in aqueous media. The effect of different factors on recovery percent, like $\mathrm{pH}$ temperature, amount of chelating agent, and amount of surfactant have been studied. A very good separation of metal ions could be achieved at different $\mathrm{pH}$ values with good effeciency of separation under the optimum conditions. The analyses of metal ions were carried out using flame atomic absorption spectrometer with duterium lamp background correction and calibration curve method curve method.

G R A P H I C A L A B S T RA C T

PROPYLENE OXIDE- ETHYLENE OXIDE BLOCK POLYMER AS A SURFACTANT FOR CLOUD POINT EXTRACTION OF SOME METAL IONS

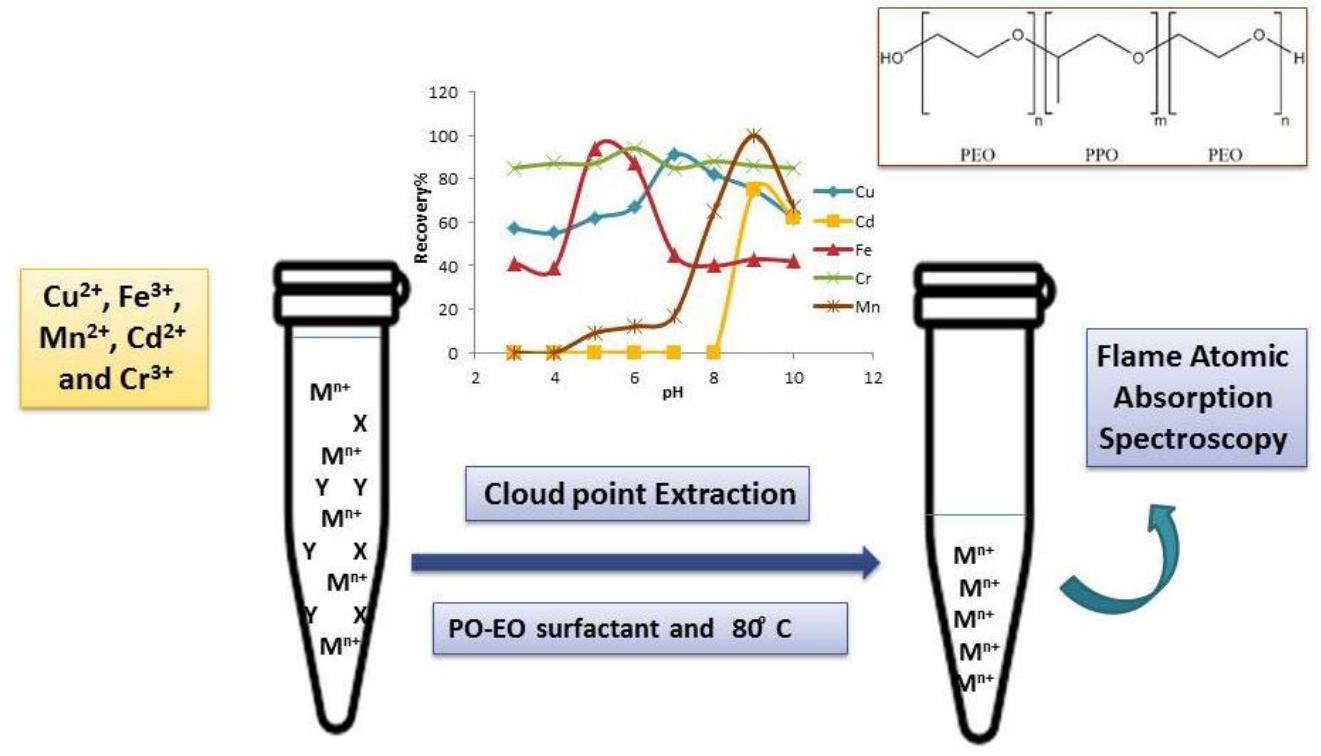

*Corresponding author's E-mail address: nabil.bader@uob.edu.ly 


\section{Introduction}

Flame atomic absorption spectrometry (FAAS) with its relative low cost and good analytical performance, is the main instrument in the research laboratories for determining a variety of heavy metals. Accurate determination of traces heavy metals by flame atomic absorption spectroscopy is the one of the important problems for the analytical chemist because of their low concentrations and the influences of the matrix of the analyzed samples. In order to overcome these problems, analytical chemists generally use separationpreconcentration techniques including liquidliquid extraction, co-precipitation, cloud point extraction, electro-deposition, and solid phase extraction [1-8].

Cloud point extraction (CPE) is based on the phase behavior of non-ionic surfactants in aqueous solutions, which exhibit phase separation after an increase in temperature or the addition of a salting-out agent. Separation and preconcentration based on cloud point extraction (CPE) are becoming an important and practical application of surfactants in analytical chemistry $[9,10]$. CPE is based on the ability of most nonionic surfactants in aqueous solutions to produce micelles and to separate into a surfactant-rich phase of a small volume and a diluted aqueous phase when heated to the cloud point temperature.

The small volume of the surfactant-rich phase produced by this methodology allows of simple, cheap, highly efficient, speedy, and of lower toxicity to the environment extraction schemes than those extractions that use the organic solvents [11]. CPE might be an interesting and efficient alternative, once it eliminates or reduces consumption of organic solvents significantly. Trace elements can be extracted to the surfactant-rich phase usually after formation of a hydrophobic complex with an appropriate chelating agent [12]. Cloud point extraction has been successfully employed to extract and preconcentrate several trace elements from different types of matrices [13-18].

In the present work a simple, selective and sensitive CPE method for preconcentration and determination of $\mathrm{Cu}^{2+}, \mathrm{Fe}^{3+}, \mathrm{Mn}^{2+}, \mathrm{Cd}^{2+}$ and $\mathrm{Cr}^{3+}$ ions in various samples using Propylene oxideEthylene oxide block polymer (PO-EO) as a surfactant and ammonium pyrrollidine dithiocarbamate (APDC) as selective complexing agent in basic media was established.

\section{Experimental}

\section{Reagents}

All solutions were prepared with deionized water. Analytical-grade methanol, acids, and other chemicals used in this study were obtained from Merck, Darmstadt, Germany. The calibration curve was established using standard solution method. A $1.0 \%(\mathrm{w} / \mathrm{v})$ of surfactant POEO from Clariant.

\section{Instruments}

A Novaa 350 atomic absorption spectrometer equipped with deuterium background correction and copper, iron, chromium, cadmium and manganese hollow-cathode lamp as the radiation source was used for absorbance measurements at wavelength respectively. The instrumental parameters were adjusted according to the manufacturer's recommendations. A Hettich centrifuge was used to accelerate the phase separation process. JENWAY mode $3150 \mathrm{pH}$ meter was used for $\mathrm{pH}$ measurements.

\section{Test procedure}

For the cloud point extraction, aliquots of 12 $\mathrm{mL}$ of the sample or standard solution containing the analyte $(10 \mathrm{~mL})$, surfactant $(1 \mathrm{~mL})$, ligand (1 $\mathrm{mL})$, were kept in thermostated water bath at $\left(60-80^{\circ} \mathrm{C}\right)$ for $15 \mathrm{~min}$. Separation of the aqueous and surfactant-rich phase was accomplished by centrifugation for $2 \mathrm{~min}$ at $3000 \mathrm{rpm}$. After cooling in the ice ( $5 \mathrm{~min}$ ), the surfactant rich phase became viscous. The supernatant aqueous 
phase was then separated completely a $10 \mathrm{~mL}$ syringe centered in the tube. The resulting solution was introduced into the flame atomic absorption spectrometer.

\section{Results and discussions}

\section{Effect of $p H$}

The $\mathrm{pH}$ plays a very important role on metalchelate formation and extraction. CPE of, copper, cadmium, manganese and iron ions was performed in solutions of $\mathrm{pH}$ ranging from $(3$ to 10). Figure 1 shows the effect of $\mathrm{pH}$ on the extraction percent.
At lower $\mathrm{pH}$, the ligand is protonated and its ionic characteristics increase and lead to decrease in its solubilization in the hydrophobic micelles. At higher $\mathrm{pH}$, the ligand is deprotonated and it behaves like a hydrophilic molecule and easily gets solubilized in the micelles. The maximum extraction efficiency was obtained at $\mathrm{pH}=5$ for $\mathrm{Fe}^{3+}, 7$ for $\mathrm{Cu}^{3+}$ and 9 for $\mathrm{Cd}^{2+}$ and $\mathrm{Mn}^{2+}$. While $\mathrm{Cr}^{3+}$ gives a fixed rate of separation at different $\mathrm{pH}$ values.

The recovery of the metal ion depends on the $\mathrm{pH}$ of complex formation and the stability of the complex at this $\mathrm{pH}$. The lower recovery of $\mathrm{Cd}^{2+}$ ion can be explained by the dynamic dissolution process of the expected mechanism of the APDC complex formation [19].
Figure 1. Effect of $\mathrm{pH}$ on the recoveries of metal ions

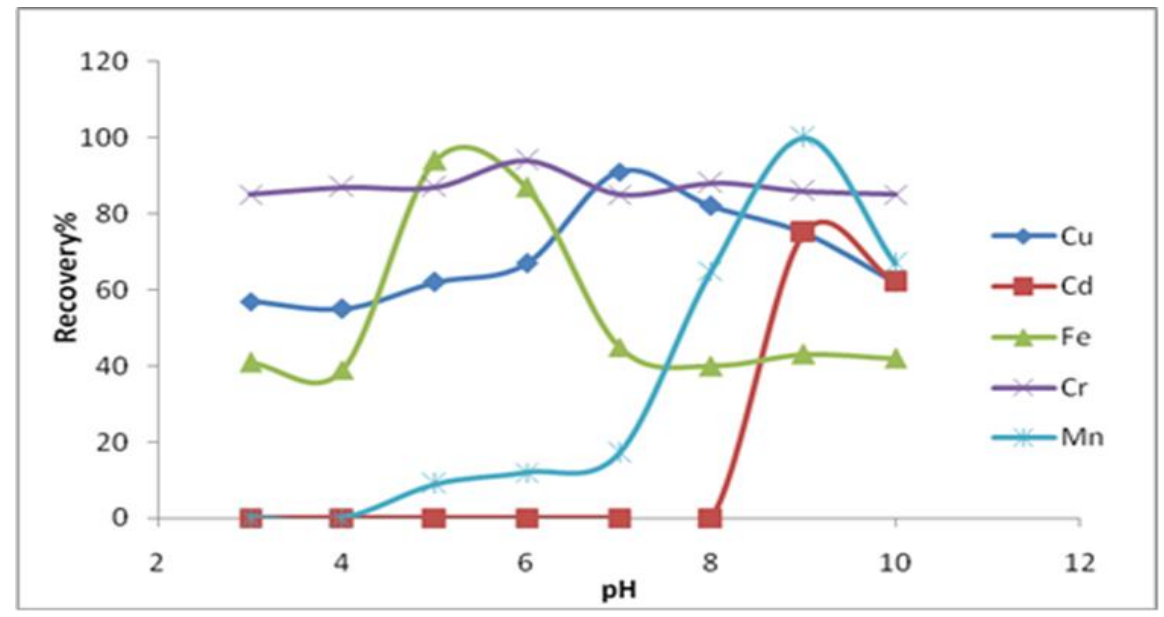

Figure 2. Effect of ligand amount

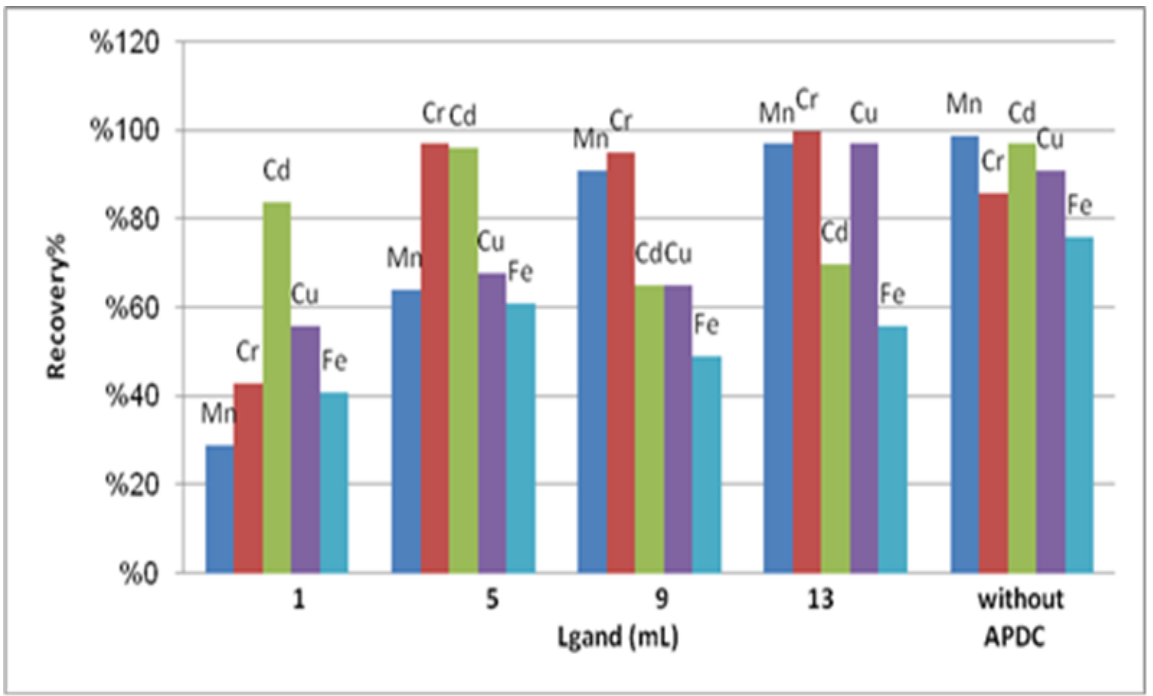




\section{Effect of APDC concentration}

The APDC was used as a complexing agent for chromium, copper, cadmium, manganese and iron ions. The effect of concentration of APDC was investigated over the range (1- 13 $\mathrm{ml})$. The relation between the extraction recovery and the APDC concentration is shown in Figure 2. In case of $\mathrm{Mn}^{2+}$ and $\mathrm{Cd}^{2+}$ separation, a very good separation could be achieved without using APDC as a chelating agent. However in case of $\mathrm{Cu}^{2+}, \mathrm{Cr}^{3+}$ and $\mathrm{Fe}^{3+}$, addition of APDC is required to attain good extraction percent.

APDC reacts with metal ion to form a nonpolar complex. The formed nonpolar complex is extracted into the nonpolar environment of micelle [19].

Effect of PO-EO surfactant volume on the recovery\%

The PO-EO surfactant was chosen because of its commercial availability in a high purified homogeneous form, low toxicological effects and low cost. Also, the high density of surfactant- rich phase facilitates phase separation by centrifugation. Additionally the cloud point $\left(60-80{ }^{\circ} \mathrm{C}\right)$ of PO-EO surfactant permits its use in the extraction and/or preconcentration of a large number of molecules and metal chelates at that temperature. The preconcentration efficiency was evaluated using PO-EO surfactant concentration ranging from 1 to $4 \mathrm{~mL}$. No change has been observed, therefore $1 \mathrm{~mL}$ was chosen for extraction procedure in order to minimize the consumption of chemicals.

\section{Effect of temperature on metal recovery\%}

The cloud point temperature of PO-EO surfactant is $\left(60-80^{\circ} \mathrm{C}\right)$ which is the preferred for cloud point temperature and analytical purposes. The maximum extraction efficiency obtained was for $\mathrm{Fe}^{3+}$ at $\left(60{ }^{\circ} \mathrm{C}\right)$, and for $\mathrm{Cd}^{2+}$ $\mathrm{Cu} 2^{+}$and $\mathrm{Cr}^{3+}$ at $\left(80^{\circ} \mathrm{C}\right)$, while $\mathrm{Mn}^{2+}$ ion gives a good of separation at wide range as shown in Figure 3.

\section{Effect of metal ions concentration on recovery\%}

The Most suitable concentration on recovery\% was studied and formed to be 10 ppm for $\mathrm{Cr}^{3+}$ and $\mathrm{Cd}^{2+}$, while 20 ppm for $\mathrm{Cu}^{2+}$, $\mathrm{Fe}^{3+}$ and $\mathrm{Mn}^{2+}$ as shown in Figure 4.

\section{Effect of centrifugation time and rates}

The effect of centrifugation time upon analytical signal was also studied for the range of (2-14 min). A centrifugation time of $2 \mathrm{~min}$ at $3000 \mathrm{rpm}$ was selected for the entire procedure, since no improvements were observed for longer time.

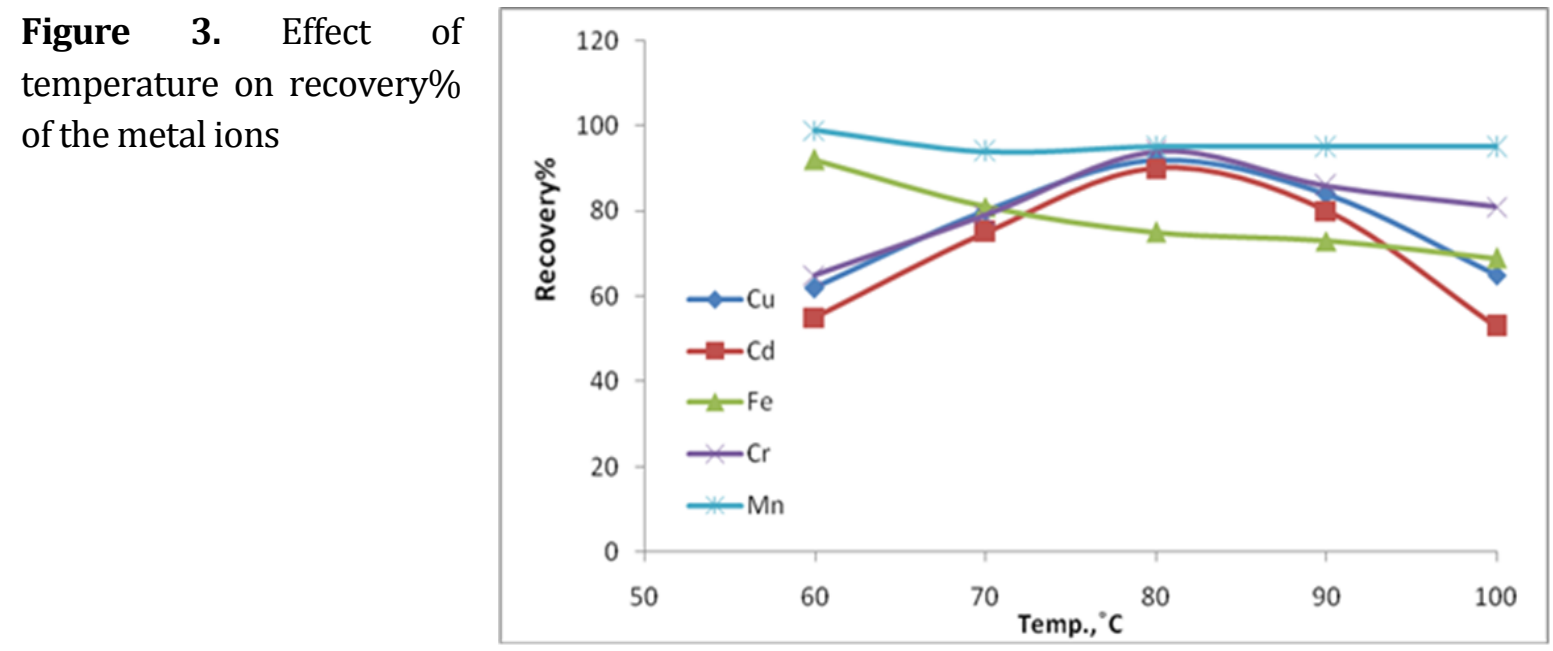


Figure 4. Effect of metal ions concentration on recovery\%

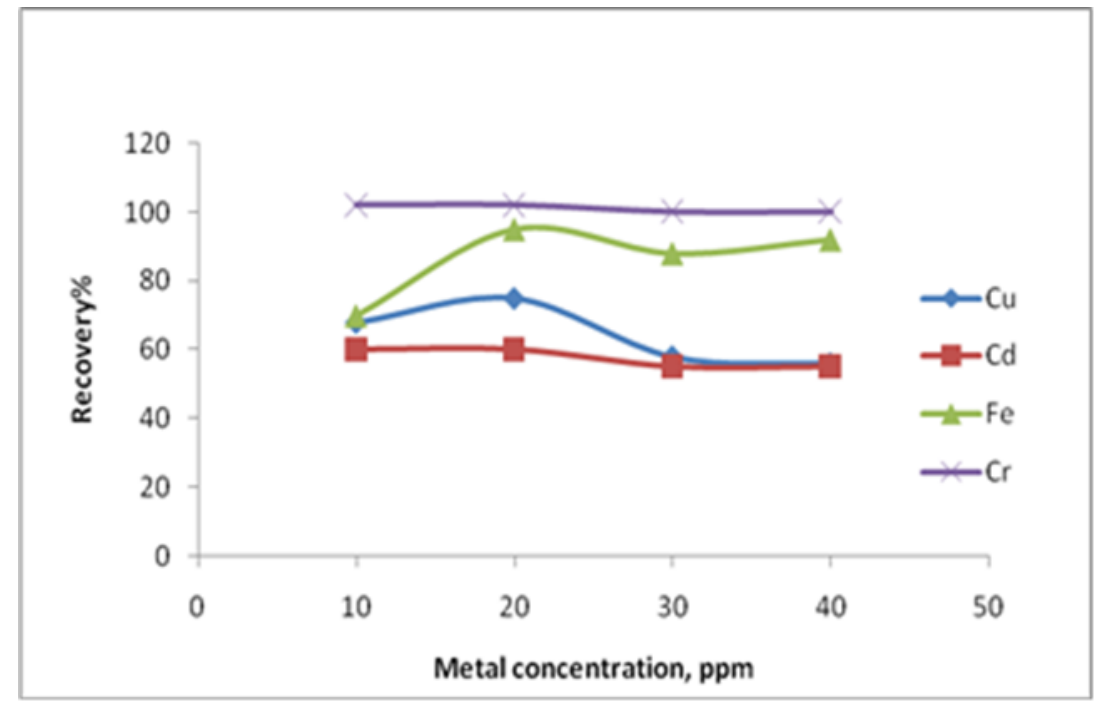

Table 1. Extraction of metal ions in certified refrence materials

\begin{tabular}{cccccc} 
Metal ions & $\mathrm{Cu}$ & $\mathrm{Cr}$ & $\mathrm{Cd}$ & $\mathrm{Fe}$ & $\mathrm{Mn}$ \\
Recovery\% & 98 & 98 & 63 & 99 & 99 \\
\hline
\end{tabular}

\section{Applications}

To verify the accuracy of the proposed method, the contents of $\mathrm{Cu}^{2+}, \mathrm{Cr}^{3+}, \mathrm{Cd}^{2+}, \mathrm{Fe}^{3+}$ and $\mathrm{Mn}^{2+}$ in certified reference material in the soil (GBW07406) were determined by the CPE method. As it shown in Table 1, the obtained results are in good agreement with the reference values.

\section{Conclusion}

The cloud point extraction offers a simple, rapid, sensitive, inexpensive, non-polluting and environmentally benign methodology which is alternative to other separation/preconcentration techniques. Oxalkylated polyamine was chosen for the formation of the surfactant rich phase due to its excellent physico-chemical characteristics. The present method can be successfully applied for the determination of cadmium, copper, chromium, iron and manganese ion in aqueous samples.

\section{Acknowledgments}

The authors wish to thank Prof. Awad Alhussadi from Chemistry department, Faculty of scienc, University of Benghazi for his help and advice.

\section{Disclosure statement}

No potential conflict of interest was reported by the authors.

\section{References}

[1] V.A. Lemos, J.S. Santos, P.X. Baliza, Sep. Sci. Tech., 2004, 39, 3317-3330.

[2] M.A. Taher, J. Anal. Chem., 2004, 59, 985-990.

[3] F. Shemirani, S.D. Abkenar, A. Khatouni, Bull. Korean Chem. Soc., 2004, 25, 1133-1136.

[4] R. Saran, T.S. Basu Baul, R. Srinivas, D.T. Khathing, Anal. Lett., 1992, 25, 1545-1557.

[5] M.A. Taher, A. Mostafavi, D. Afzali, E. Rezaeipour, Bull. Korean Chem. Soc., 2004, 25, 1125-1129.

[6] N.R. Bader, Rasayan J. Chem., 2011, 4, 49-55.

[7] F.M. El-sharief, A.A. Asweisi, N.R. Bader, Asian J. Nanosci. Mater., 2019, 2, 149-158. 
[8] a) A.M.M. Ahmed, A.E. Ali, A.H. Ghazy, Adv. J. Chem. A, 2019, 2, 79-93; b) Z. Zamiraei, M. Golzar, H. Hamidi, 2018, 1, 105-116.

[9] F.H. Quina, W.L. Hinze, Ind. Eng. Chem. Res., 1999, 38, 4150-4168.

[10] M.A. Bezerra, R.E. Bruns, S.L.C. Ferreira, Anal. Chim. Acta, 2006, 580, 251-257.

[11] N.R. Bader, K. Edbey, U. Telgheder, J. Chem. Pharm. Res., 2014, 6, 496-501

[12] H. Filik, F. Dondurmacioglu, R. Apak, Int. J. Environ. Anal. Chem. 2008, 88, 637-648.

[13] Y.J. Li, B. Hu, Z.C. Jiang, Anal. Chim. Acta., 2006, 576, 207-214.

[14] T.A. Maranhão, D.L.G. Borges, M.A. Veiga, A.J. Curtius, Spectrochim. Acta B, 2005, 60, 667-672.

[15] F. Shemirani, S.D. Abkenar, A.A. Mirroshandel, M.S. Niasari, R.R. Kozania, Anal. Sci., 2003, 19, 1453-1456.
[16] H. Sang, P. Liang, D. Du, J. Hazard. Mater. 2008, 154, 1127-1132.

[17] A.A. Asweisi, A. Shahen, M. Boajela, Cloud point extraction using some commercially available surfactants for separation of some metal ions from aqueous solution, Colloquium Analytische Atomspektroskopie CANAS, Germany, 2013.

[18] A. Asweisi, R. Hussein, Oxalkylated polyamine as a surfactant for separation of some metal ions from aqueous solutions by cloud point extraction Abdelsalam. first conferenvace on chemical science and its application, 21-23 April 2014, Omar ElMukhtar University, Albaida, Libya.

[19] S.K. Lee, H.S. Choi, Bull. Korean Chem. Soc., 2001, 22, 463-466.

How to cite this manuscript: Abdelsalam Asweisi, Rihab Hussein, Nabil Bader, Rajab Elkailany, Propylene Oxide-Ethylene Oxide Block Polymer as a Surfactant for Cloud Point Extraction of Some Metal Ions, Adv. J. Chem. A, 2020, 3(3), 259-264. 